\title{
Cholesterol Profile and Gut Microbial Population of Laying Hens Treated with L-Dopa Supplemented Diets
}

\author{
Babatunde Richard Oluwasegun Omidiwura*, Adebisi Favour Agboola, and Adeola Rukayat Adelu \\ Department of Animal Science, University of Ibadan, Nigeria \\ "Corresponding author’s Email: richardwura@ gmail.com; ORCID: 0000-0001-6823-2922
}

\begin{abstract}
In a 42-day feeding trial, the effect of L-Dopa on the performance, serum cholesterol and intestinal microbial load in laying hens were investigated. One hundred and twenty layers aged 34 weeks old were allocated to five dietary treatments with eight replicates and three birds per each replicate. The birds were fed diets supplemented with graded levels of L-Dopa $(0,0.1,0.2,0.3$ and $0.4 \%)$ in a completely randomized design. Performance parameters were monitored. On the day 42, egg, meat and blood samples were obtained to determine total cholesterol and lipoproteins using standard procedures. The ileal digesta was collected for microbial analysis. The results indicated that inclusion of L-Dopa in the diet did not affect the performance parameters and egg cholesterol profile. Serum cholesterol levels of birds fed the control diet and those on $0.1 \%$ and $0.2 \%$ L-Dopa supplemented diets were similar, but significantly higher than those fed $0.3 \%$ and $0.4 \%$ L-Dopa. The levels of cholesterol and low-density lipoproteins in the meat of the layers fed on the control diet were significantly higher than those on $0.1 \%$ and $0.3 \%$ L-Dopa, but were similar to the birds on other treatment diets. The highest and the lowest population of Escherichia coli were found in the birds on the control diet and $0.3 \%$ L-Dopa supplemented diet, respectively. The layer hens on L-Dopa supplemented diets had a significantly higher Lactobacillus count than those on the control diet. In conclusion, 0.3\% L-Dopa inclusion considerably improved the cholesterol profile in the blood and meat, reduced the population of $E$. coli, and effectively increased the population of Lactobacillus in the laying hens.
\end{abstract}

Key words: Cholesterol profile, Layers, Levodopa, Microbial load, Performance

\section{INTRODUCTION}

Among the anti-nutritional factors in raw velvet beans (Mucuna pruriens), L-Dopa (3, 4-dihydroxyphenylalanine) has been proved to have a marked effect on the growth response in some poultry species (Meites et al., 1977). In birds, L-Dopa is naturally produced through the biosynthesis of L-tyrosine in the presence of tyrosine hydroxylase. Lampariello et al. (2012) reported that supplementation of L-Dopa in the diet increased dopamine levels in the body. Meites et al. (1977) stated that L-Dopa could pass through the blood-brain barrier, where it becomes decarboxylated to dopamine that is effective in stimulating the hypothalamus and hypophysis to release and increase the level of the growth hormone. Administration of L-Dopa could correct the retardation in the reproductive activity related to hypothalamic catecholamine deficiency in aging rats (Quadri et al., 1973).

It was also reported that feeding with substantial levels of L-Dopa significantly increased brain dopamine levels (Wilson and Meier, 1989) which affected the neuroendocrine-gonadal axis, resulting in changes of the body growth and reproductive conditions. The injection of L-Dopa in Japanese quails stimulated testicular and ovarian development as well as the production of folliclestimulating hormone and luteinizing hormone (Prasad et al., 2007). Also, an intravenous injection of L-Dopa had a lowering effect on the cholesterol levels in the blood and eggs of the poultry (Meier and Wilson, 1998). An earlier study indicated that L-Dopa reduced gastrointestinal motility, and also the activity of lymphocytes (Shultz, 2007). As a pharmacologically active ingredient, the ingestion of large amounts of L-Dopa could be toxic (Pieriset et al., 1980). However, it was reported that levels of 0.1 to $0.4 \%$ L-Dopa inclusion had no detrimental effect on broiler hens (Omidiwura et al., 2016; Omidiwura et al., 2017; Omidiwura, 2019). Additionally, Omidiwura (2019) reported that an inclusion in the diet improved serum cholesterol profile and performance of the broiler chickens. It is worthy to note that each region of the gastrointestinal tract developed its special microbial profile, and this community became more complex with 
increasing age of the chicken (Gong et al., 2002). Omidiwura et al. (2015) studied the influence of L-Dopa on the gut mucosa integrity of broiler chickens, and found that L-Dopa improved the villus to crypt depth ratio. Regarding the previous findings on the efficacy of L-Dopa in growth and reproductive performances in some poultry species, the present study aimed to investigate the effect of L-Dopa on the performance and intestinal microbial population of laying birds. Furthermore, this study evaluated the impacts of L-Dopa supplements on the cholesterol levels in blood, egg, and meat.

\section{MATERIALS AND METHODS}

\section{Ethical approval}

The project was in compliance with the policy document of the University of Ibadan, Nigeria, on research ethics and requirements for animal handling.

\section{Study design}

The study was conducted at the poultry unit of Teaching and Research Farm, University of Ibadan, Ibadan, Nigeria. One hundred and twenty laying birds (34week-old) were obtained from the poultry unit of Teaching and Research Farm, University of Ibadan. The birds were tagged, weighed, and randomly allocated to five dietary treatments with eight replicates and three birds per replicate in a completely randomized design. Feed and water were supplied ad libitum to the hens in the cages during the study period. Recommended vaccines and other medications were administered, and routine management practices strictly adhered to the six-week study. The proximate composition of treatment diets is shown in table 1. Treatment 1 was the control diet, a basal diet without LDopa while treatments 2, 3, 4, and 5 contained the basal diets and L-Dopa at inclusion levels of $0.1 \%, 0.2 \%, 0.3 \%$, and $0.4 \%$, respectively. The L-Dopa used in the experiment was a pure extract from Mucuna pruriens seed.

\section{Data collection}

Feed intake

The feed intake was calculated by deducting the amount of leftover feed from the total feed given.

\section{Feed conversion ratio}

Feed Conversion Ratio (FCR) was calculated as the weight of feed consumed divided by the unit egg weight.

\section{Hen-day egg production}

Hen-day egg production was calculated as the total number of eggs produced during the period divided by total number of hens alive during the same period.

\section{Lipid measurement}

For egg yolk cholesterol quantification, three eggs per replicate were prepared according to the procedure described by Elkin and Rogler (1990). Total cholesterol, High-Density Lipoprotein (HDL), and total triglyceride concentration in the egg yolk were determined using the respective cholesterol assay kit. Low-Density Lipoprotein (LDL) and Very Low-Density Lipoprotein (VLDL) were calculated as described by Friedewald et al. (1972).

Using two hens per replicate, the serum cholesterol level was determined using serum cholesterol kit (Cell Biolabs' HDL and LDL/VLDL Cholesterol Assay Kit) according to the procedure described by Siedel et al. (1981). At the end of the experiment, two hens per replicate were sacrificed and breast meat samples were collected for analysis of cholesterol level in meat. Approximately $2 \mathrm{~g}$ of sample was saponified according to a modified version of the method described by Stewart et al. (1992).

\section{Intestinal microbial load}

Two birds per replicate were sacrificed and ileal digesta was collected for intestinal microbial load evaluation. The microbial count was done using the method described by Barrow and Feltharn (1993).

\section{Statistical analysis}

Data were analyzed using descriptive statistics and GLM procedure in SAS software (SAS Institute Inc., USA) and among treatments, means differences were separated using Duncan's multiple range test at $P=0.05$.

Table 1. Proximate chemical composition of control and treatment diets supplemented with L-Dopa

\begin{tabular}{lccccc}
\hline Item & Control diet & $\mathbf{0 . 1 \%}$ L-Dopa & $\mathbf{0 . 2 \%}$ L-Dopa & $\mathbf{0 . 3 \%}$ L-Dopa & 0.4\% L-Dopa \\
\hline Metabolisable energy (kcal/kg) & 2755 & 2761 & 2756 & 2755 & 2745 \\
Dry matter (\%) & 93.14 & 93.11 & 93.05 & 93.20 & 93.21 \\
Crude protein (\%) & 16.94 & 15.12 & 16.40 & 16.49 & 17.83 \\
Crude fiber (\%) & 3.20 & 3.30 & 3.10 & 3.20 & 3.10 \\
Ether extract (\%) & 7.30 & 8.20 & 7.50 & 7.50 & 7.50 \\
Ash (\%) & 15.00 & 11.00 & 14.00 & 17.00 & 18.00 \\
Nitrogen free extract (\%) & 50.70 & 55.49 & 52.05 & 49.01 & 46.78 \\
\hline
\end{tabular}




\section{RESULTS AND DISCUSSION}

\section{Production performance}

The effects of L-Dopa supplemented diets on the performance of layers are shown in Table 2. There were no significant $(\mathrm{p}>0.05)$ differences in terms of FCR, feed intake, and egg weight among the treatments. This finding is in agreement with a study conducted by Omidiwura et al. (2017) who found that the feed intake, weight gain, and FCR were not significantly influenced by L-Dopa inclusion in broiler diets, but contradicts the findings of Vadivel and Pugalenthi (2010) and Omidiwura (2019). Also, this study revealed that the supplementation of LDopa in tested levels had no significant effect on the henday egg production of layers. This was not in line with the results obtained by Wilson and Meier (1989), who reported that feeding considerable levels of L-Dopa resulted in changes in body growth and reproductive performance. Bhatt and Chaturvedi (1993) also revealed that dopaminergic activity may affect the neuroendocrinegonadal axis which could induce and maintain reproductive conditions.

\section{Lipid profile}

The effect of L-Dopa supplemented diets on blood cholesterol of laying birds is shown in Table 3. The LDopa inclusion had no effect on HDL and LDL of birds on the treatment diets. There were significant differences in triglycerides and total serum cholesterol $(\mathrm{p}<0.05)$. As the level of L-Dopa increased in the diet the level of triglycerides and cholesterol tended to decrease. Although birds fed $0.2 \%, 0.3 \%$ and $0.4 \%$ L-Dopa supplemented diets had similar concentrations of triglycerides and VLDL. Cholesterol levels of birds fed the control diet and $0.1 \%$ L-Dopa supplemented diets were similar but significantly higher than those fed $0.3 \%$ and $0.4 \%$ L-Dopa supplemented diets. This finding showed that the L-Dopa lowered the triglycerides and total serum cholesterol values. This may be a result of an increase in availability of norepinephrine and epinephrine, supplied by L-Dopa supplementation, which is involved in the hydrolysis of triglyceride. Carew et al. (2003) reported a reduction in serum cholesterol may be due to the adsorption of intestinal cholesterol by dietary fiber and rapid excretion of some other components in Mucuna. Similar reports by Jayaweera et al. (2010) suggested that Mucuna pruriens had a strong cholesterol-lowering effect in broilers.
The significant effect of L-Dopa on VLDL was in line with the findings of Iauk et al. (1993) who observed a reduction in blood cholesterol when birds were fed raw Mucuna based diets.

\section{Egg cholesterol concentration}

The effect of L-Dopa diet supplementation on egg cholesterol of laying birds is shown in Table 4. No significant differences in terms of the cholesterol, triglycerides, HDL, LDL, and VLDL were observed among the treatment diets. Contrarily, Prasad et al. (2007) reported that the incorporation of L-Dopa in the feed of poultry reduced the cholesterol content and also the ratio of saturated to unsaturated fatty acids in eggs.

\section{Lipid profile of chicken meat}

The lipid profile of meat produced by laying hens fed L-Dopa supplemented diets is shown in Table 5. There were no significant differences in terms of triglyceride concentration in meat. The HDL level in the meat of birds fed $0.1 \%$ L-Dopa supplemented diets was significantly higher than that those fed other diets. The Cholesterol and LDL concentration in birds fed the control diet was significantly higher than $0.1 \%$ and $0.3 \%$ L-Dopa supplemented diets but similar to other diets. The inclusion of L-Dopa at $0.3 \%$ dietary level reduced the level of cholesterol and LDL in the meat.

\section{Intestinal microbial population}

The result of L-Dopa supplemented diets on the intestinal microbial population of layers is shown in Table 6. Significant differences were observed in the microbial population of E. coli and Lactobacillus. Population of E. coli $(\mathrm{p}<0.05)$ was highest $\left(7.25 \times 10^{4} \mathrm{cfu} / \mathrm{mL}\right)$ in birds on the control diet and was least $\left(1.35 \times 10^{4} \mathrm{cfu} / \mathrm{mL}\right)$ in birds fed $0.3 \%$ L-Dopa diet. Treatment diets did not influence the total coliform count. Lactobacillus count was significantly $(\mathrm{p}<0.05)$ higher in birds on L-Dopa supplemented diets compared to the control diet. According to the results, the population of E. coli in the control diet was higher than that in the diet supplemented with $0.1 \%, 0.2 \%, 0.3 \%$ and $0.4 \%$ L-Dopa. This simply means that L-Dopa greatly reduced the population of $E$ coli in the laying birds. Moreover, L-Dopa inclusion in diet had a significant effect on the population of Lactobacillus in the layers. Intestinal Lactobacillus 
population of birds on L-Dopa supplemented diets in $0.1 \%$ and $0.2 \%$ inclusion levels were found to be higher than that of chickens on other diets. The population of Lactobacillus was found to be the lowest in layers fed the control diet. This finding indicates that for an effective increase in the population of Lactobacillus, a diet needs little quantity of L-Dopa supplementation. The information on the influence of L-Dopa on animal's gut microbiota is very scanty. However, the study by Rekdal et al. (2019) on the treatment efficacy of L-Dopa in Parkinson's disease suggested possible interplay between L-Dopa and human gut microbiota. The current study showed the efficacy of L-Dopa in improving the gut integrity of laying hens.

Table 2. The effects of diets supplemented with graded levels of L-Dopa on the performance of laying hens

\begin{tabular}{|c|c|c|c|c|c|c|c|}
\hline \multirow{2}{*}{ Characteristics } & \multicolumn{5}{|c|}{ L-Dopa inclusion level (\%) } & \multirow{2}{*}{ SEM } & \multirow{2}{*}{$P$-value } \\
\hline & $\mathbf{0 . 0}$ & 0.1 & 0.2 & 0.3 & 0.4 & & \\
\hline Hen-day egg production (\%) & 83.93 & 82.44 & 79.76 & 84.62 & 81.15 & 3.26 & 0.83 \\
\hline Daily feed intake (g/hen) & 101.87 & 98.65 & 103.18 & 102.52 & 100.48 & 1.75 & 0.39 \\
\hline FCR (g/feed/g/egg) & 0.91 & 0.92 & 1.18 & 0.85 & 1.16 & 0.15 & 0.35 \\
\hline Egg weight (g) & 58.26 & 57.49 & 60.65 & 60.73 & 61.76 & 1.92 & 0.48 \\
\hline
\end{tabular}

SEM: Standard Error of Mean. FCR: Feed Conversion Ratio

Table 3. The effects of diets supplemented with graded levels of L-Dopa on lipid profile of laying hens

\begin{tabular}{|c|c|c|c|c|c|c|c|}
\hline \multirow{2}{*}{ Parameter (mg/dL) } & \multicolumn{5}{|c|}{ L-Dopa inclusion level (\%) } & \multirow{2}{*}{ SEM } & \multirow{2}{*}{$P$-value } \\
\hline & 0.0 & 0.1 & 0.2 & 0.3 & 0.4 & & \\
\hline Triglyceride & $337.06^{\mathrm{a}}$ & $331.63^{\mathrm{a}}$ & $286.30^{\mathrm{b}}$ & $255.21^{b}$ & $254.02^{b}$ & 15.30 & 0.0003 \\
\hline HDL & 10.23 & 7.67 & 12.97 & 8.031 & 6.15 & 2.52 & 0.3687 \\
\hline Total serum cholesterol & $107.51^{\mathrm{a}}$ & $102.32^{\mathrm{a}}$ & $83.74^{\mathrm{ab}}$ & $48.09^{c}$ & $64.65^{\mathrm{bc}}$ & 10.09 & 0.0007 \\
\hline LDL & 20.24 & 26.33 & 20.01 & 9.31 & 15.08 & 4.85 & 0.1647 \\
\hline VLDL & $67.41^{\mathrm{a}}$ & $66.33^{\mathrm{a}}$ & $57.26^{\mathrm{b}}$ & $51.04^{\mathrm{b}}$ & $50.80^{\mathrm{b}}$ & 3.06 & 0.0003 \\
\hline
\end{tabular}

Means in the same row with different superscript letters are significantly $(\mathrm{p}<0.05)$ different; SEM= Standard Error of Mean; HDL: High-Density Lipoprotein; LDL: Low-Density Lipoprotein; VLDL: Very Low-Density Lipoprotein

Table 4. Lipid profile of eggs from laying hens fed on diets supplemented with graded levels of L-Dopa

\begin{tabular}{|c|c|c|c|c|c|c|c|}
\hline \multirow{2}{*}{ Parameter (mg/dL) } & \multicolumn{5}{|c|}{ L-Dopa inclusion level (\%) } & \multirow{2}{*}{ SEM } & \multirow{2}{*}{$P$-value } \\
\hline & $\mathbf{0}$ & 0.1 & 0.2 & 0.3 & 0.4 & & \\
\hline Cholesterol & 88.77 & 63.00 & 100.30 & 94.37 & 72.23 & 10.33 & 0.1084 \\
\hline Triglycerides & 429.06 & 378.67 & 417.58 & 435.05 & 400.34 & 39.66 & 0.8509 \\
\hline HDL & 5.58 & 5.79 & 11.38 & 9.37 & 6.92 & 2.68 & 0.5038 \\
\hline LDL & 4.64 & 0.00 & 11.05 & 15.22 & 3.89 & 6.38 & 0.4829 \\
\hline VLDL & 85.81 & 75.73 & 82.77 & 87.01 & 80.07 & 8.11 & 0.8638 \\
\hline
\end{tabular}

SEM= Standard Error of Mean. HDL: High-Density Lipoprotein; LDL: Low-Density Lipoprotein; VLDL: Very Low-Density Lipoprotein

Table 5. The effects of diets supplemented with graded levels of L-Dopa on lipid profile of chicken meat

\begin{tabular}{lccccccc}
\hline \multirow{2}{*}{ Parameter (mg/dL) } & \multicolumn{9}{c}{ L-Dopa inclusion level (\%) } & \multirow{2}{*}{ SEM } & \multirow{2}{*}{$\boldsymbol{P}$-value } \\
\cline { 2 - 5 } & $\mathbf{0}$ & $\mathbf{0 . 1}$ & $\mathbf{0 . 2}$ & $\mathbf{0 . 3}$ & $\mathbf{0 . 4}$ & & 0.4569 \\
Triglyceride & 31.38 & 33.89 & 43.05 & 32.22 & 41.56 & 5.58 & $<0.0001$ \\
Cholesterol & $177.33^{\mathrm{a}}$ & $87.12^{\mathrm{b}}$ & $205.52^{\mathrm{a}}$ & $60.31^{\mathrm{b}}$ & $171.81^{\mathrm{a}}$ & 17.1 & $<0.0001$ \\
HDL & $5.35^{\mathrm{b}}$ & $17.50^{\mathrm{a}}$ & $6.18^{\mathrm{b}}$ & $5.28^{\mathrm{b}}$ & $5.29^{\mathrm{b}}$ & 1.07 & $<0.0001$ \\
LDL & $165.71^{\mathrm{a}}$ & $57.84^{\mathrm{b}}$ & $190.74^{\mathrm{a}}$ & $48.58^{\mathrm{b}}$ & $158.21^{\mathrm{a}}$ & 16.53 & $<0.0001$ \\
\hline
\end{tabular}

Means in the same row with different superscript letters are significantly different (p < 0.05). SEM: Standard Error of Mean; HDL: High-Density Lipoprotein; LDL: Low-Density Lipoprotein. 
Table 6. The effect of L-Dopa supplementation on intestinal microbial population of 40 weeks-old layers

\begin{tabular}{|c|c|c|c|c|c|c|c|}
\hline \multirow{2}{*}{ Bacterial count $\left(\times 10^{4} \mathrm{cfu} / \mathrm{ml}\right)$} & \multicolumn{5}{|c|}{ L-Dopa inclusion level (\%) } & \multirow{2}{*}{ SEM } & \multirow{2}{*}{$P$-value } \\
\hline & $\mathbf{0}$ & 0.1 & 0.2 & 0.3 & 0.4 & & \\
\hline$E$-coli & $7.25^{\mathrm{a}}$ & $3.38^{\mathrm{b}}$ & $3.08^{\mathrm{b}}$ & $1.35^{\mathrm{c}}$ & $2.75^{\mathrm{b}}$ & 1.97 & $<0.0001$ \\
\hline Total Coliform & 4.75 & 3.00 & 2.60 & 3.18 & 5.25 & 5.09 & 0.039 \\
\hline Lactobacillus & $2.05^{\mathrm{b}}$ & $6.98^{\mathrm{a}}$ & $7.00^{\mathrm{a}}$ & $5.50^{\mathrm{a}}$ & $4.88^{\mathrm{a}}$ & 3.74 & $<0.0001$ \\
\hline
\end{tabular}

Means in the same row with different superscript letters are significantly different $(\mathrm{p}<0.05)$. SEM: Standard Error of Mean.

\section{CONCLUSION}

The present study demonstrated that the dietary supplementation of L-Dopa, especially at $0.3 \%$ level, improved the lipid profile in the blood and meat. Also, this study showed the efficacy of L-Dopa in improving the gut integrity of laying hens. Dietary L-Dopa supplementation at 0.1 to $0.4 \%$ did not have any deleterious effect on the performance of layers. It is recommended that further studies should be conducted to investigate the influence of L-Dopa in other species of poultry.

\section{DECLARATIONS}

\section{Acknowledgments}

The authors acknowledge the contribution of Animal Production Venture of the Teaching and Research Farm, University of Ibadan, Nigeria for providing the laying hens used in this study.

\section{Authors' contributions}

All authors were involved in planning and execution of the study. Omidiwura B. R. O prepared the manuscript and others reviewed it.

\section{Competing interests}

No competing interest exists.

\section{REFERENCES}

Barrow GH and Feltham RKA (1993). Cowan and Steel's Manual for Identification of Medical Bacteria. Third edition. Cambridge University Press, Cambridge, p. 331.DOI: https://dx.doi.org/10.1017/CBO9780511527104

Bhatt R and Chaturvedi R (1993). L-DOPA treatment induces scotosensitivity in Japanese quail. Journal of Reproductive Biology and Comparative Endocrinology, 5: 75-83. Available at: http://www.biomedcentral.com/1477-7827/

Carew LB, Hardy D, Weis J, Alster FA, Mischler SA, Gernat AG and Zakrzewska EI (2003). Heating raw velvet beans (Mucuna pruriens) revers some antinutritional effects on organ growth, blood chemistry, and organ histology in growing chickens. Tropical and Subtropical Agroecosystems, 1(2): 267-275. Available at: http://citeseerx.ist.psu.edu/viewdoc/download?doi=10.1.1.1009.39 $\&$ rep=rep $1 \&$ type $=$ pdf
Elkin RG and Rogler JC (1990). Reduction of the cholesterol content of eggs by the oral administration of lovastatin to laying hens. Journal of Agricultural and Food Chemistry, 38 (8): 1635-1641. DOI: https://doi.org/10.1021/jf00098a003

Friedewald WT, Levy RI and Fredrickson DS (1972). Estimation of the concentration of low-density lipoprotein cholesterol in plasma without use of preparative ultra-centrifuge. Clinical chemistry, 18 (6):499-502. Available https://www.ncbi.nlm.nih.gov/pubmed/4337382

Gong G, Entekhabi D and Cohen J (2002) A large-ensemble model study of the wintertime AO/NAO and the role of interannual snow perturbations. Journal of Climate, 15: 3488-3499.Available at: http://web.mit.edu/jlcohen/www/papers/Gong.pdf

Iauk L, Galati EM, Kirjavainem S, Forestieri AM, and Trovato A (1993). Analgesic and antipyretic effects of Mucuna pruriens. International Journal of Pharmacognosy, 31: 213-216. DOI: https://doi.org/10.3109/13880209309082944

Jayaweera, T, Cyril H, Samarasinghe K, Ruwandeepika, H, Wickramanayake D and Thotawaththe T (2010). Effect of feeding velvet beans (Mucuna pruriens) on the lipid profile of broiler chickens. Sabaragamuwa University Journal, 7(1):78-85. DOI: http://doi.org/10.4038/suslj.v7i1.1845

Lampariello LR, Alessio CR, Guerranti CS and Giuseppe V (2012). The magic velvet bean of Mucuna pruriens. Journal of Traditional and Complementary Medicine, 2(4): 331-339. DOI: 10.1016/s22254110(16)30119-5

Meier AH and Wilson JM (1998). Method of altering the contents of eggs. Louisiana State University and Agricultural and Mechanical College. Publication of EP0836474A1. European Patent Office. Available at:https://patents.google.com/patent/EP0836474A1/en

Meites, J, Simpkins J, Bruni J and Advis J (1977). Role of biogenic amines in control of anterior pituitary hormones. IRCS Journal of Medical Sciences, 5: 1-7. Available at:http://pascalfrancis.inist.fr/vibad/index.php?action=getRecordDetail\&idt=PASC AL7750343674

Omidiwura BRO (2019). Effect of L-Dopa in replacing Dl-methionine on the performance of broiler chickens. Journal of Experimental $\begin{array}{llll}\text { Agriculture International, 29(2): 1-8. } & \text { DOI: }\end{array}$ https://doi.org/10.9734/JEAI/2019/45401

Omidiwura BRO, Agboola AF and Akogun OA (2017). Effect of L-Dopa on performance and serum cholesterol of Nera black pullets. Nigerian Journal of Animal Production, 44(3):254 - 261.

Omidiwura BRO, Agboola AF, Adeoye MK and Iyayi EA (2015). Influence of L-Dopa of Mucuna pruriens on growth response and gut mucosa integrity of broiler chickens. The Proceedings of the British Society of Animal Science.

Omidiwura BRO, Odu O, Agboola AF, Akinbola DD and Iyayi EA (2016). Crude protein and energy requirements of Japanese quail (Coturnixcoturnix japonica) during rearing period. Journal of World Poultry Research, 6(2): 99-104. Available at: http://jwpr.scienceline.com/attachments/article/37/J\%20World\%20Poult\%20Res\%206 (2)\%2099-104,\%202016.pdf 
Pieris N, Jansz ER and Dharmadasa HM (1980). Studies on mucuna species of Sri Lanka1 - The L-Dopa content of seeds. Journal of the National Science Council of Sri Lanka, 8: 35-40. Available at: $\mathrm{http} / / /$ agris.fao.org/agris-

search/search.do?recordID=US201301299396

Prasad SK, Qureshi, TN., Sexana S, Qureshi S., Mehar M and Thakur SK (2007). L-Dopa feeding induces body growth and reproductive conditions in Japanese quail, Coturnixcoturnix Japonica. International Journal of Poultry Science, 6 (8): 560-566. Available at:http://free-journal.umm.ac.id/files/file/L-

Dopa $\% 20$ Feeding\%20Induces\%20Body\%20Growth\%20and\%20Re productive.pdf

Quadri SK, Kledzik GS and Meites J (1973). Re-initiation of estrous cycles in old constant estrous rats by central acting drugs. Neuroendocrinology, 11 : 248-255. DOI:https://doi.org/10.1159/000122137

Rekdal VM, Bess EN, Bisanz JE, Turnbaugh PJ and Balskus EP (2019). Discovery and inhibition of an interspecies gut bacterial pathway for Levodopa metabolism. Science, 364: 1-8. DOI: https://doi.org/10.1126/science.aau6323
Shultz (2007). Multiple dopamine function at different time course. Annual Review of Neuroscience, 30:259-288. DOI: https://doi.org/10.1146/annurev.neuro.28.061604.135722

Siedel J, Schlumberger H, Klose S, Ziegenhorn J and Wahlefeld AW (1981). Improved reagent for the enzymatic determination of serum cholesterol. Journal of Clinical. Chemistry and Biochemistry, 19: 838-847. Available at: https://ci.nii.ac.jp/naid/10005390924/

Stewart G, Gosselin C and Pandian S (1992). Selected ion monitoring of tert-butyldimethylsilyl cholesterol ethers for determination of total cholesterol content in foods. Food Chemistry, 44: 377-380. DOI: https://doi.org/10.1016/0308-8146(92)90271-3

Vadivel V and Pugalenthi M (2010). Evaluation of growth performance of broiler birds fed with diet containing different levels of effectively processed velvet bean seeds collected from South India. Livestock Science, 127: 76-83. DOI: 10.1016/j.livsci.2009.09.002

Wilson JM and Meier AH (1989). Resetting the annual cycle with timed daily injections of 5-hydroxytryptophan and 1dihydroxyphenylalanine in Syrian hamsters. Chronobiology International, 6:2, 113-121. https://doi.org/10.3109/07420528909064621 